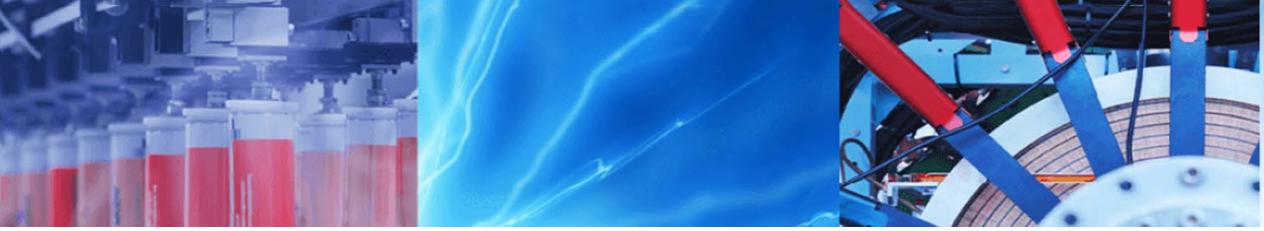

Research Article

\title{
A statistical analysis of IRMS and CRDS methods in isotopic ratios of ${ }^{2} \mathrm{H} /{ }^{1} \mathrm{H}$ and ${ }^{18} \mathrm{O} /{ }^{16} \mathrm{O}$ in water
}

\author{
Tárcio Henrique Ribeiro dos Santos ${ }^{1} \cdot$ Maria do Rosário Zucchi ${ }^{2}$. Thierry Jacques Lemaire ${ }^{2}$. \\ Antonio Expedito Gomes de Azevedo ${ }^{2}$. Denise Nunes Viola ${ }^{3}$
}

(c) Springer Nature Switzerland AG 2019

\begin{abstract}
Quantitative information about the variation in natural isotopic abundances in water is of great importance in a variety of fields. Due to the wide range of applications and types of samples, it is necessary that isotopic analyses have precision, accuracy and reproducibility. The present study compares the techniques of cavity ring-down spectroscopy (CRDS) and isotope-ratio mass spectrometry (IRMS) for the determination of the isotopic ratios of ${ }^{2} \mathrm{H} /{ }^{1} \mathrm{H}$ and ${ }^{18} \mathrm{O} /{ }^{16} \mathrm{O}$ in water in the two secondary standards, denoted PB3 and PB4, and in a certified material, GISP, Greenland Ice Sheet Precipitation, used as a quality tester of such measurements. The traditional method for measuring isotopic ratios is IRMS. Because of the nature of the molecule, the samples are not introduced directly into the mass spectrometer. Instead, the water is chemically converted to $\mathrm{CO}_{2}$ and $\mathrm{H}_{2}$. The other technique, $\mathrm{CRDS}$, is a system of laser absorption that has great potential for the detection of atomic and molecular species with high sensitivity by measuring the light absorption ratio as a function of time, confined within an optical cavity of high finesse. In this technique, the water sample is converted into steam without undergoing conversion processes. Parametric (test $T$ ) and nonparametric (Wilcoxon) statistical tests were performed to compare the results obtained in the system, and CRDS and IRMS are from the same population. The values of the isotopic abundances of the two secondary standards [PB3, $\delta \mathrm{D}=-1.9 \pm 0.4(\%)$ and $\delta^{18} \mathrm{O}=-2.19 \pm 0.24(\%)$ and PB4, $\delta^{2} \mathrm{H}=-71.4 \pm 0.4(\%)$ and $\left.\delta^{18} \mathrm{O}=-10.08 \pm 0.19(\%)\right]$ were determined with accuracy. For the certified standard GISP, values of $\delta^{2} \mathrm{H}=-189.3 \pm 0.5(\%)$ and $\delta^{18} \mathrm{O}=-24.69 \pm 0.20(\%)$ were obtained. Both techniques have factors that interfere with the accuracy of the measurements and require corrections. Comparing the results revealed that there was a greater accuracy for measurements with CRDS and greater precision for IRMS. However, the results are within the tolerance range of $0.2 \%$ for $\delta^{18} \mathrm{O}$ and $2.0 \%$ for $\delta^{2} \mathrm{H}$ in isotope hydrology.
\end{abstract}

Keywords CRDS · IRMS · Isotopic ratios

\section{Introduction}

Stable and radioactive isotopes are ideal tracers in a wide range of research fields. The measurements of the ratios of ${ }^{2} \mathrm{H} /{ }^{1} \mathrm{H}$ and ${ }^{18} \mathrm{O} /{ }^{16} \mathrm{O}$ in water are some of the most important applications of isotope-ratio mass spectrometry.
The results were expressed in \%o (per mil) in relation to Vienna Standard Mean Ocean Water (VSMOW):

$\delta X=\left[\left(R_{\text {Sample }}-R_{\text {Standart }}\right) / R_{\text {Standart }}\right] \times 1000(\% 0)$,

where $X={ }^{18} \mathrm{O}$ (oxygen) or ${ }^{2} \mathrm{H}$ (deuterium) and $R={ }^{18} \mathrm{O} /{ }^{16} \mathrm{O}$ for oxygen and ${ }^{2} \mathrm{H} /{ }^{1} \mathrm{H}$ for deuterium.

Maria do Rosário Zucchi, mrzucchi@ufba.br; Tárcio Henrique Ribeiro dos Santos, tarcio.santos@ifba.edu.br; Thierry Jacques Lemaire, thierry.lemaire@ufba.br; Antonio Expedito Gomes de Azevedo, expedito@ufba.br; Denise Nunes Viola, viola@ufba.br | ${ }^{1}$ Instituto Federal da Bahia (IFBA), Campus Valença, Valença, Bahia, Brazil. ${ }^{2}$ Instituto de Física, Universidade Federal da Bahia (UFBA), Salvador, Bahia, Brazil. ${ }^{3}$ Instituto de Matemática, Universidade Federal da Bahia (UFBA), Salvador, Bahia, Brazil.

SN Applied Sciences (2019) 1:664 | https://doi.org/10.1007/s42452-019-0635-9

Received: 23 January 2019 / Accepted: 16 May 2019 / Published online: 4 June 2019 
Quantitative information about the natural variations in the isotopic abundances in water is an indispensable research tool that can be applied to various fields, such as hydrology, palaeoclimatology, atmospheric physics, geochemistry and the metabolic study of biomedicine for humans and animals and in forensic research [1-4]. Due to this wide variety of applications and thus sample types, the analysis of isotopic variations presents high precision as well as accuracy and reproducibility. New methods for isotope analysis are being proposed, and older methods are being improved. The conventional method used for more than 40 years in the analysis of isotopic abundances is isotope-ratio mass spectrometry (IRMS).

A relatively new technique, applied in the determination of the abundances of stable isotopes, has been used on a large scale. This is cavity ring-down spectroscopy (CRDS), a laser absorption technique that has great potential for the detection of atomic and molecular species with a high sensitivity. In CRDS, a laser pulse is stored on an optical cavity that contains the sample, and the pulse decay is monitored by a detector that measures the intensity of the light transmitted through one of the mirrors [5].

The aim of this study was to compare the effectiveness of the CRDS and IRMS techniques regarding precision and accuracy. It was conducted with two different laboratory water standards, denoted PB3 and PB4. The international standard, GISP, was used as a quality tester. Finally, statistical tests, the $T$ test and the Wilcoxon-Mann-Whitney test, were performed with $\mathrm{R}$ software [6] to determine whether the measurements performed with IRMS and CRDS are equal.

The goal of the statistical analysis in this paper is to determine the values of $\delta^{18} \mathrm{O}$ and $\delta^{2} \mathrm{H}$ in the secondary standards, PB3 and PB4, and in the international standard, GISP, used as a calibration quality control and to quantify the dispersion of the data. To obtain this result, the same procedure of inter-laboratory comparison exercise used by the International Atomic Energy Agency, IAEA, and conducted in [7-10], was adopted. These exercises evaluated the performance (precision and accuracy) of individual laboratories regarding the reference values of $\delta^{18} \mathrm{O}$ and $\delta^{2} \mathrm{H}$ of previously determined samples. With that, the value of standard reference GISP was determined.

The statistical treatment consists of two stages: The first stage evaluates the measurements, ruling out the disparate values or outliers based on the frequency distribution of the values after determining the upper and lower quartiles and the inter-quartile range. The values that went through this stage provide a provisional average. In the second stage, the accuracy and precision of the results are examined. First, the results were evaluated based on the difference between the observed isotopic value, $\delta_{(i)}$, and the provisional average, $m$, divided by the standard deviation, $s_{i}$, of each observed isotope value. The results with $\left|\left(\delta_{i}-m\right)\right| / s_{i}$ values of more than two were discarded. This procedure tests the accuracy of a measurement based on your own precision given by the standard deviation. The second stage assessed if the measurements, disregarding their deviations, were accurate within the tolerance of $\pm 0.2 \%$ and $\pm 2.0 \%$ in relation to the reference values for $\delta^{18} \mathrm{O}$ and $\delta^{2} \mathrm{H}$, respectively, in studies of isotope hydrology.

\section{Isotope-ratio mass spectrometer (IRMS)}

In this work, IRMS measurements were performed using a Thermo Finnigan MAT Plus DELTA model. Here, the magnetic sector-type mass has a maximum intensity of $0.75 \mathrm{~T}$, covering a range of up to 70 amu for a maximum acceleration voltage of $3 \mathrm{kV}$. In instruments for isotopic measurements of light elements such as $\mathrm{H}, \mathrm{C}, \mathrm{N}, \mathrm{O}$ and $\mathrm{S}$, the magnetic fields are created by electromagnets that are configured to keep the magnetic field B fixed. With this, you can focus a beam of ions with a given $\mathrm{m} / \mathrm{q}$ ratio in a sink by varying the accelerating voltage of the ions and the magnetic field.

A sample of water cannot be introduced directly into the source of ionization because water vapour is not compatible with the vacuum system of IRMS. Samples must undergo a process of chemical conversion or exchange to produce specific gases that are analysed in the spectrometer.

For measurements of $\delta^{18} \mathrm{O}$, the method proposed by [11] was applied in the sample preparation. This method establishes isotope equilibrium between known isotopic ratios of carbonic gas with $0.3 \% \mathrm{He}$ and $0.5 \mathrm{ml}$ of water at a constant temperature of $25.0^{\circ} \mathrm{C}$ for a period of one to 2 days at rest.

The process of balance occurs in small jars placed in a GasBench II system, Thermo Finnigan, coupled to the mass spectrometer.

During the time of equilibrium isotopic exchange between water and $\mathrm{CO}_{2}$, if the molar quantity of $\mathrm{CO}_{2}$ is much smaller than that of the water, then, after the time of balance, the $\delta^{18} \mathrm{O}$ is transferred to the carbon dioxide. Finally, the $\mathrm{CO}_{2}$ gas, marked with the $\delta^{18} \mathrm{O}$ from the water sample, is sent in a continuous stream through an interface open split to the isotope-ratio mass spectrometer for analysis. This interface of the GasBench II system, Thermo Finnigan, manages the entry of the reference gas and the sample, as well as the injection and dilution in the spectrometer. For each vial, 15 peaks are obtained, the first 5 being the reference gas and the last 10 being isotopically marked $\mathrm{CO}_{2}$ gas. The resulting $\delta^{18} \mathrm{O}$ value is an average of 
these 10 peaks. For the correction of the $\delta^{18} \mathrm{O}$ in $\mathrm{CO}_{2}$, the method proposed by Craig is used [12].

To determine the $\mathrm{D} / \mathrm{H}$ ratio, we used the method presented by Brand et al. [13], which proposed transforming water into hydrogen by reducing the water to hundreds of degrees Celsius with chrome metal. Approximately 1.0$\mu \mathrm{l}$ aliquots of the water sample are injected into a reactor H/DEVICE connected to the Thermo Finnigan mass spectrometer, where the chromium oxidation reaction occurs at $850^{\circ} \mathrm{C}$ and $\mathrm{H}_{2}$ is released.

Unlike the $\mathrm{CO}_{2}$, the $\mathrm{H}_{2}$ resulting from the above reaction is not sent on a continuous flow to the mass spectrometer. $\mathrm{H}_{2}$ was analysed using a dual-inlet system [14].

The hydrogen isotopic composition is given by the ratio between a mass of $3 \mathrm{amu}\left({ }^{2} \mathrm{H}^{1} \mathrm{H}\right)$ and a mass of $2 \mathrm{amu}$ $\left({ }^{1} \mathrm{H}^{1} \mathrm{H}\right)$. However, the source of ionization induces the formation of the ion $\mathrm{H}_{3}{ }^{+}$, which contributes to the signal of the $\mathrm{H}^{2} \mathrm{H}^{+}$ion by increasing the ratio of the masses. To avoid this influence, must determine the $\mathrm{H}_{3}{ }^{+}$factor, whose unit is given in $\mathrm{ppm} / \mathrm{mV}[14,15]$.

\section{Infrared spectrometry-CRDS}

The experimental apparatus consists of a Picarro L2120 model-I spectrometer for the isotope analysis of water, containing a ring-down type resonant cavity of $25 \mathrm{~cm}$, formed by three highly reflective mirrors with an effective optical length of approximately $25 \mathrm{~km}$ and a laser source operating at approximately $1.39 \mu \mathrm{m}$ (Fig. 1). After cleaning sequences, evacuation and filling the cavity with $\mathrm{N}_{2}$ gas to $99.999 \%$ purity, approximately $2 \mu$ of water is injected

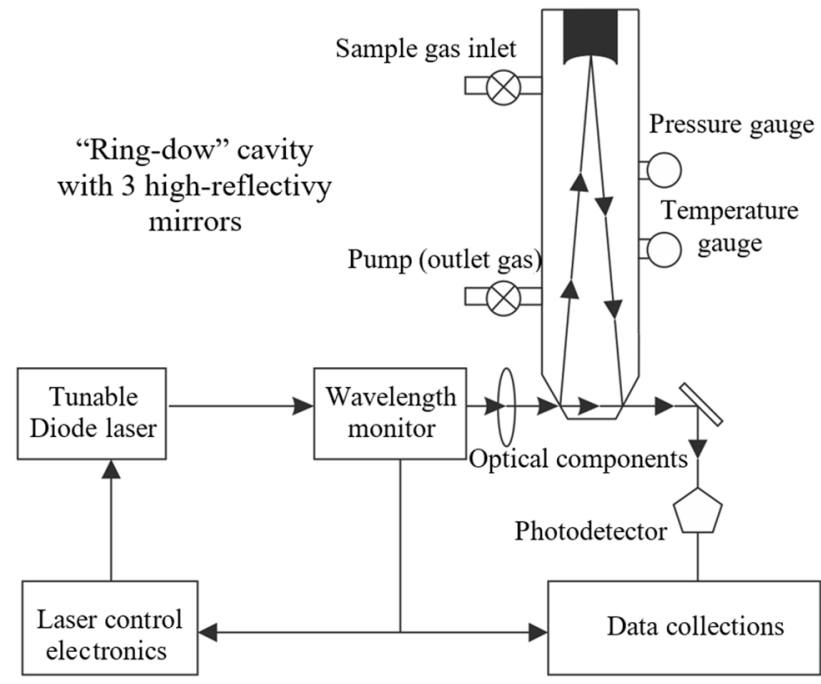

Fig. 1 Schematic diagram (Source: Modified from www.PICAR RO.com) in a vaporizer maintained at $110^{\circ} \mathrm{C}$. In the steamer, the water vapour is mixed with $\mathrm{H}_{2}$, forming a homogeneous mixture for $90 \mathrm{~s}$, which is sent to the analyser in a steady stream of $30 \mathrm{ml} / \mathrm{min}$.

Most relatively small molecules that are of environmental interest, at room temperature and low pressure in the gas phase, reveal infrared absorption spectra. The resulting spectra are highly sensitive to the isotopic substitution of molecules. In general, all optical techniques depend on the record of spectral characteristics that can be exclusively attributed to the isotopes of interest [16].

CRDS is a direct absorption spectroscopic technique of high sensitivity based on the determination of a time constant for the exponential decay of light emitted from the optical cavity. A small amount (ppm) of the light pulse enters the cavity for transmission, which is mostly reflected [17]. In conventional absorption spectroscopic techniques, determining the absorption coefficient is more time-consuming because it is related to the measurement of an intensity ratio, whereas in CRDS, the absorption coefficient is related to the measurement of the rate of absorption of light circulating in the cavity.

The analysis of the spectra and vibrational states can determine the relative abundance of isotopes because the vibrational frequency depends on the masses of the atoms in the molecule through the reduced mass. Therefore, if a sample has two isotopic species, the vibrational frequencies and power levels will be slightly different for the two types of molecules. Their spectral lines, consequently, will be displaced from each other. By measuring the spectral intensities, i.e. the isotope effect, it is possible to obtain the relative abundance of the two isotopes, similar to the values obtained in mass spectrometry.

The decay of a light pulse injected into the cavity is monitored by a detector that measures the intensity transmitted through one of the mirrors. This is expressed as a simple exponential decay due to molecular absorption and loss in the mirrors. The attenuation of light travelling through the sample is measured, and the intensity transmitted through the cavity follows the Beer-Lambert law.

The intensity measured by the photodetector decays exponentially as a function of time, being the decay time ring-down

$\tau=\frac{L}{c(1-R)}$

where $L$ is the length of the cavity, $c$ is the speed of light and $R$ is the reflectance of the mirrors.

A small fraction of the light is transmitted through one of the mirrors to the detector for each complete cycle.

The ring-down time is defined by

$$
\tau=\frac{L}{c(1-R+\alpha L)}
$$


where $\alpha$ is the coefficient of absorption.

However, strictly speaking, one should consider the extinction due to light scattering and absorption by the various species present in the cavity. These contributions are represented by the coefficient of absorption, which depends on the frequency: $\alpha(v)$. Therefore, a more general expression for the time of ring-down is given by:

$\tau=\frac{L}{c\left[1-R(v)+\sum_{i} \sigma_{i}(v) \int_{0}^{L} N_{i}(x) \mathrm{d} x\right]}$

where the sum is performed over all the species $i$ with frequency-dependent absorption or section and the density of the integrated line number. If the absorption is due to a single species, it implies that $\alpha(v)=N(v)$, where $N$ is the density of the absorber (number of molecules per unit volume) and $\sigma(v)$ is the cross section of absorption.

The exponential decay of ring-down is obeyed when the characteristic absorption line width is much broader than the line width of light circling the cavity. If the line width of the pulse is wider than the width of an absorption line, only those frequencies that are in resonance will be absorbed by the sample and attenuated by the mirrors, whereas the out-of-resonance frequencies are attenuated by the mirrors. This generally causes no exponential decay [5].

The sample fills the entire cavity so that the absorption coefficient can be obtained by subtracting the losses in a cavity with a sample from the losses in a cavity without a sample $\alpha=0$.

$\alpha(v)=\frac{1}{c}\left(\frac{1}{\tau(v)}-\frac{1}{\tau_{0}(v)}\right)$

Such a relationship shows that the absorption does not depend on the length of the cavity or any other parameters. The absolute measurement of molecular absorption is determined by the measurement of two decay rates or two ring-down times ( $t$ and $\left.t_{0}\right)$, as shown in Fig. 2.

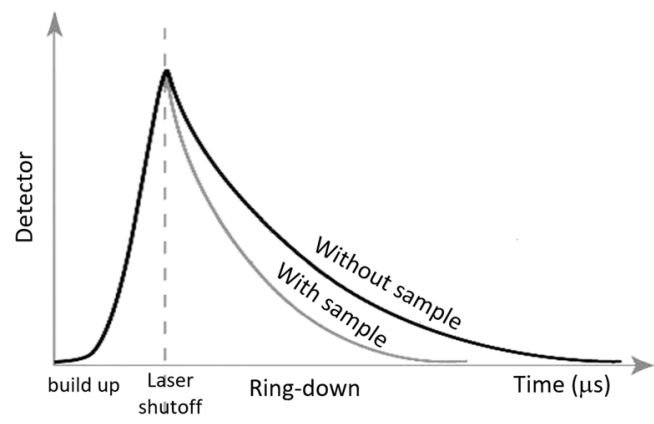

Fig. 2 Time to "Ring Down" (Source: Modified from www.PICAR RO.com)
After the "laser shutoff", no light is injected into the cavity during the measurement of the decay rate, so the technique is practically immune to laser noise.

\section{Results and discussion}

IRMS is the most commonly used technique to measure isotope ratio. However, to study water samples with IRMS, water cannot be introduced directly into the mass spectrometer and must prepared according to the methods described by $[11,13]$ to obtain $\mathrm{CO}_{2}$ and $\mathrm{H}_{2}$. Chemical conversion can also introduce errors in the measurement, and then, correction must be applied. In particular, the reduction of $\mathrm{H}_{2}$ is accompanied by a comprehensive fraction that, combined with the $\mathrm{H}_{3}^{+}$factor correction, provides even more precision in the determination of $\delta^{2} \mathrm{H}$. The typical accuracy of this method is of $1 \%$ o. The $\mathrm{H}_{3}^{+}$factor must remain constant for a series of measurements to determine the ${ }^{2} \mathrm{H} / \mathrm{H}$ ratio with a precision of $<0.5 \%$. Therefore, as the $\mathrm{H}_{3}^{+}$factor cannot be determined with the required accuracy, it is advisable to measure a series of samples with the same $\mathrm{H}_{3}^{+}$factor. The advantage lies in the fact that the errors in the precise knowledge of the $\mathrm{H}_{3}^{+}$ factor can be corrected by adjusting the differences measured with known differences of a pair of patterns, i.e. the VSMOW-SLAP scale.

In CRDS, the preparation of the water sample is not necessary. Water rates are injected in a vaporizer to produce steam that is sent to the analyser together with a drag gas $\left(\mathrm{N}_{2}\right)$. The optical cavity, a system of measurement based on the ring-down time, does a scan of the selected spectral lines to quantify the spectral characteristics of the molecules in the gas phase, specifically the absorption lines only for ${ }^{1} \mathrm{H}^{16} \mathrm{O}^{1} \mathrm{H},{ }^{1} \mathrm{H}^{18} \mathrm{O}^{1} \mathrm{H}$ and ${ }^{1} \mathrm{H}^{16} \mathrm{O}^{2} \mathrm{H}$. A careful selection of spectral characteristics is important to ensure that there is no interference from other species with similar absorption. A temperature control is also important because the intensity of the line depends on the number of molecules in the lower level of the transition, and a change in temperature redistributes the population of the rotational levels of the fundamental vibrational state [18].

A similar absorption for the different isotopes is desired to promote a comparable signal to noise ratio for all spectral lines of interest within a narrow wavelength range, limited by the laser band tuning [19]. With the decay timebased measurement of the intensity of the light beam, it is possible to determine the coefficient of absorption and consequently the isotopic values of hydrogen and oxygen, simultaneously. Figure 3 shows a typical spectrum with spectral characteristics belonging to the four isotopologues of interest. Each isotopologue exhibits characteristic of absorption for a specific spectrum range. According 


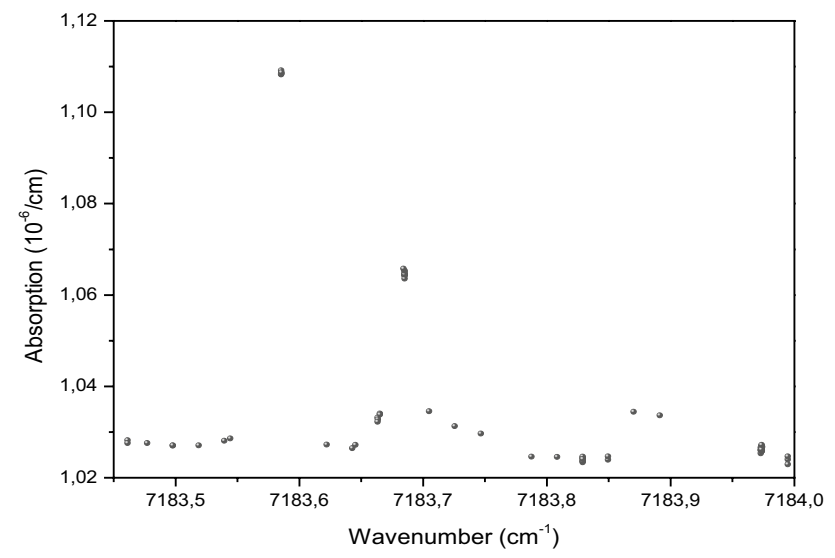

Fig. 3 Absorption spectrum of the isotopic species of water. Absorptions due to $\mathrm{H}_{2}^{18} \mathrm{O}, \mathrm{H}_{2}^{16} \mathrm{O}$ and ${ }^{1} \mathrm{H}^{2} \mathrm{HO}$

to database HITRAN 2014 [20], the first peak is due to the absorption of $\mathrm{H}_{2}^{18} \mathrm{O}$, the second is due to the absorption of $\mathrm{H}_{2}^{16} \mathrm{O}$, and the third is due to the two absorptions close to $\mathrm{H}_{2}^{16} \mathrm{O}$ and ${ }^{1} \mathrm{H}^{2} \mathrm{HO}$.

However, in the laser measurements, there is a large memory effect that must be considered when conducting the measurements. As the cavity cannot be evacuated quickly because it would cause condensation in the mirrors, thus reducing the reflectivity, other methods should be used to reduce the memory effect. The new water sample is mixed with the remnants of the previous sample due primarily to the adsorption of water on the walls of the steamer. The viscous nature of the water provides a great memory effect, as shown in Fig. 4. The values of $\delta^{18} \mathrm{O}$ obtained after the fifth measurement are distributed randomly around the unit, eliminating any memory effect correction. However, for $\delta^{2} \mathrm{H}$, the ratio between the measured value and the average value tends to asymptotic units according to the adjustment function $y=y_{0}+a e^{b x}$. A correction factor shall be determined for each $n$th as a sequence of the same sample. Figure 5 shows the random behaviour of $\delta^{18} \mathrm{O}$ around the unit or the median value, as well as the asymptotic behaviour of $\delta^{2} \mathrm{H}$. Checking the normality of the data using $\mathrm{R}$ software [6] revealed that the isotopic values for $\delta^{18} \mathrm{O}$ follow a normal distribution with a significance level $p$ value $=0.3203$ after omitting the first three measurements. The values for $\delta^{2} \mathrm{H}$ do not have a normal distribution until nine measurements are omitted. This implies the need for a correction for $\delta^{2} \mathrm{H}$ because they involve approximately eight steps in an analysis.

A gradual decrease in interference (the memory effect) is noted after the first measurements. Such interference can be performed, assuming that the water adsorption occurs in the layers. The upper layers mix easily and cause the rapid variation seen in the first steps. The deeper layers generate slower variations. It is not possible to remove
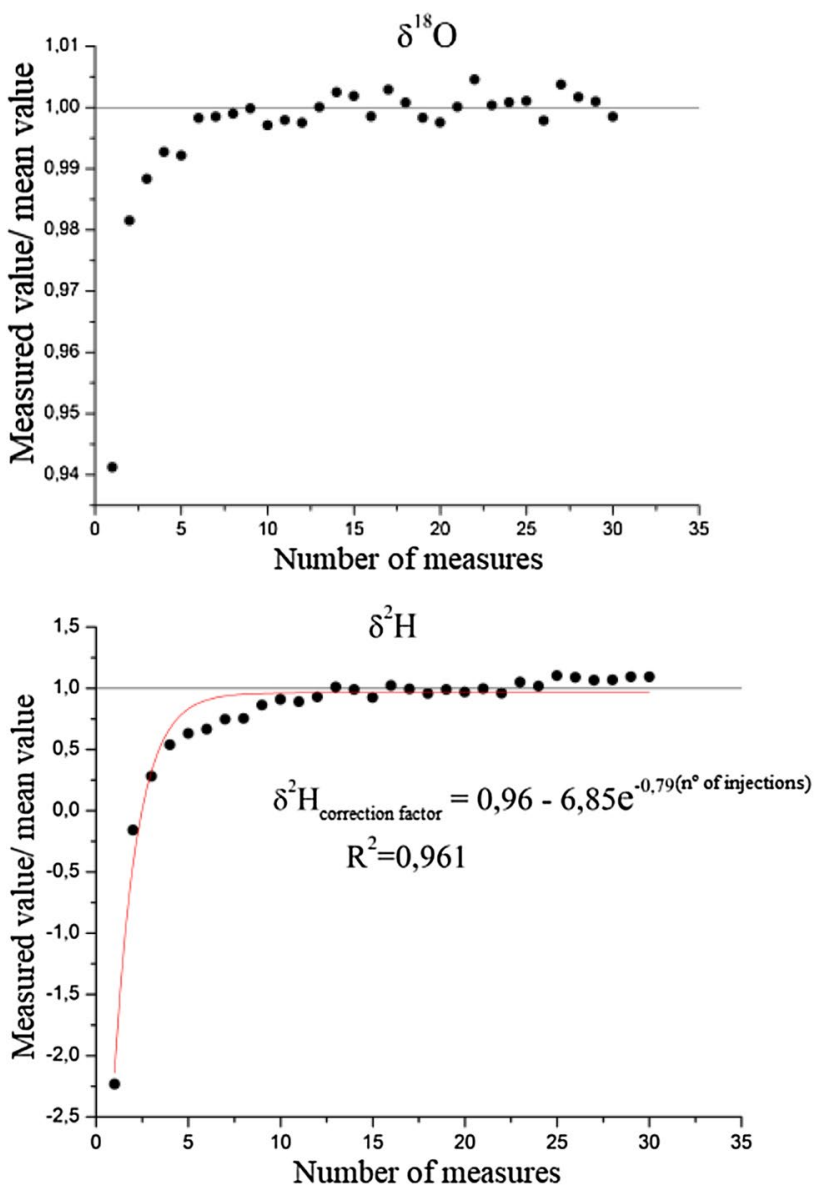

Fig. 4 Memory effect test for CRDS. In the analysis, the first steps were slightly dispersed in relation to the standard line

IE and immediately clean the system for the next sample injection. The cleaning process is done by vacuum pumps that remove some of the water molecules. Cleaning the optical cavity cannot be very fast, as this may cause condensation on the mirrors due to the rapid expansion of gas.

The memory effect is controlled by considering the number of measurements and the order in which the samples are injected. The results of the first measurements of a sequence are rejected, and samples are sequenced to minimize the influence of the previous sample on the following sample; for this purpose, a work routine was adopted that interleaves samples and patterns with empties (the injection of air or a water sample with isotopic values close to the previous sample). This decreases the influence of the SLAP standard with values of $\delta^{2} \mathrm{H}=-427.5 \%$ and $\delta^{18} \mathrm{O}=-55.5 \%$, on the next sample (unknown) and the sample on the VSMOW. The memory effect between samples of the same array can be disposed, being a limiting factor of the accuracy of laser-based systems. 

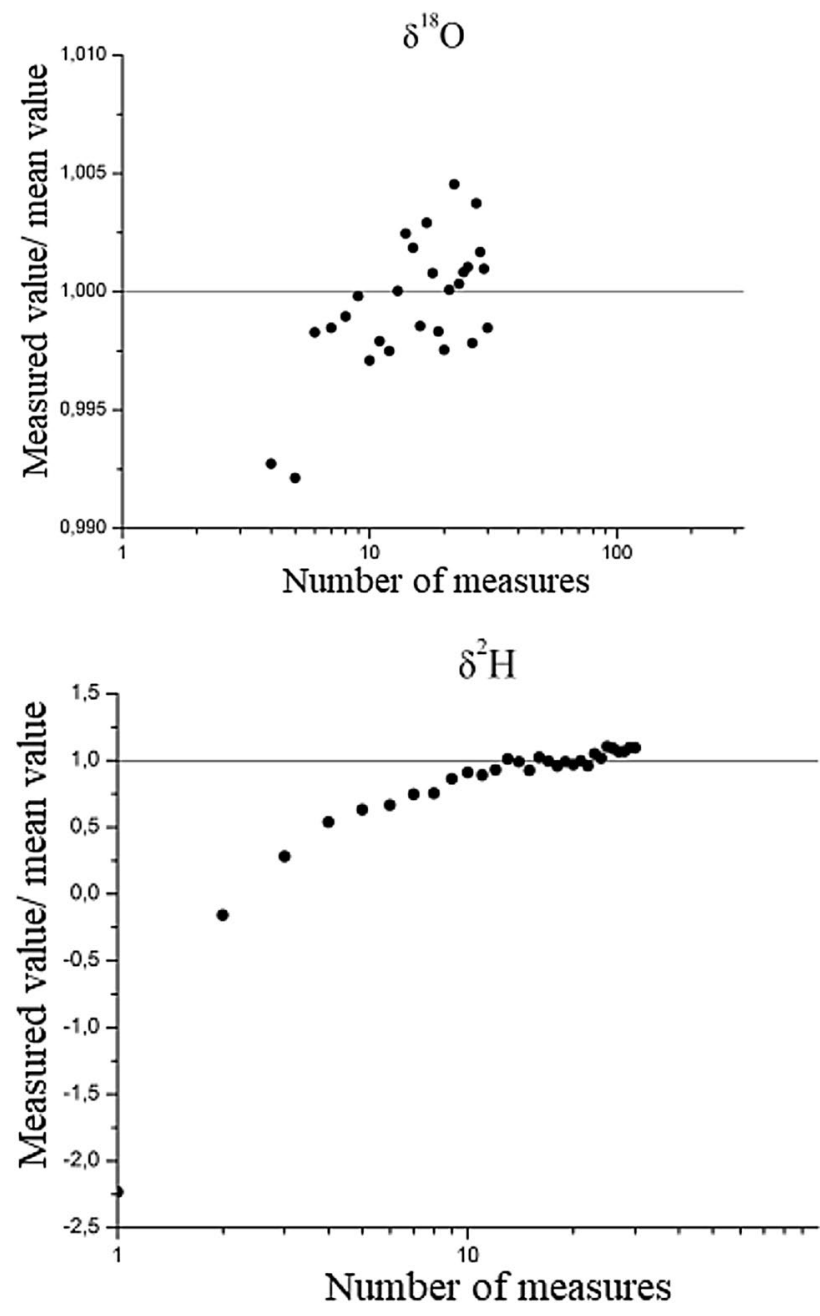

Fig. 5 Memory effect test for CRDS on a logarithmic scale

In traditional mass spectrometry, the memory effect is also present. The effect appears due to gas adsorption on solder, copper gaskets and the joints of polymers. The ion source must be chemically inert gases $\left(\mathrm{CO}_{2}\right.$ and $\left.\mathrm{H}_{2}\right)$. The hot filament can change the composition of the gas, and the reaction with $\mathrm{CO}_{2}$ in the presence of a pulse of $\mathrm{H}_{2} \mathrm{O}$ in the carbides can form ions. In addition, carbide tungsten oxide is formed on the surface of the filament by interaction with $\mathrm{CO}_{2}, \mathrm{O}_{2}$ or $\mathrm{H}_{2} \mathrm{O}$ [21]. The hydrogen gas reacts with the oxide layers on the filament, producing traces of water that temporarily generate an extra signal $\mathrm{H}_{3}^{+}$factor. Therefore, when configuring the equipment to measure $\mathrm{H}_{2}$ after having measured $\mathrm{CO}_{2}$, it is necessary to wait for hours until the filament and the equipment as a whole are conditioned. The memory effect can be tested by measuring two samples of different isotopic compositions in series and checking the transition between them. There was no significant memory effect in measurements conducted with IRMS.
Table 1 Isotopic values of the default certificate and secondary patterns GISP, PB3 and PB4 for the CRDS and IRMS methods without the application of the statistical method

\begin{tabular}{lllll}
\hline Samples & \multicolumn{1}{l}{ CRDS } & $N$ & \multicolumn{1}{l}{ IRMS } & $N$ \\
\hline$\delta^{18} \mathrm{O}_{\text {VSMOW-SLAP }} \pm \mathrm{S}_{\delta}(\% \circ)$ & & & \\
PB3 & $-2.18 \pm 0.28$ & 93 & $-2.32 \pm 0.41$ & 98 \\
PB4 & $-10.10 \pm 0.29$ & 90 & $-10.08 \pm 0.22$ & 98 \\
GISP & $-24.68 \pm 0.24$ & 47 & $-24.52 \pm 0.24$ & 38 \\
$\delta^{2} \mathrm{H}_{\text {VSMOW-SLAP }} \pm \mathrm{S}_{\delta}(\% \circ)$ & & & \\
PB3 & $-2.0 \pm 0.5$ & 43 & $-2.0 \pm 0.5$ & 57 \\
PB4 & $-71.6 \pm 0.9$ & 56 & $-71.2 \pm 0.3$ & 51 \\
GISP & $-189.3 \pm 0.8$ & 31 & $-189.3 \pm 0.5$ & 20 \\
\hline
\end{tabular}

$N$ is the number of measurements performed

Table 2 Isotopic values for the default GISP and work patterns PB3 and PB4 for the CRDS and IRMS methods with the application of the statistical treatment

\begin{tabular}{lllll}
\hline Samples & \multicolumn{1}{l}{ CRDS } & $N$ & \multicolumn{1}{l}{ IRMS } & $N$ \\
\hline$\delta^{18} \mathrm{O}_{\text {VSMOW-SLAP }} \pm \mathrm{S}_{\delta}(\% 0)$ & & & \\
PB3 & $-2.14 \pm 0.24$ & $93(65)$ & $-2.25 \pm 0.27$ & $98(37)$ \\
PB4 & $-10.10 \pm 0.21$ & $90(68)$ & $-10.09 \pm 0.17$ & $98(44)$ \\
GISP & $-24.77 \pm 0.18$ & $47(33)$ & $-24.53 \pm 0.19$ & $38(37)$ \\
$\delta^{2} \mathrm{H}_{\text {VSMOW-SLAP }} \pm \mathrm{S}_{\delta}(\%)$ & & & \\
PB3 & $-2.0 \pm 0.4$ & $43(38)$ & $-1.9 \pm 0.2$ & $57(34)$ \\
PB4 & $-71.7 \pm 0.5$ & $56(39)$ & $-71.2 \pm 0.3$ & $51(45)$ \\
GISP & $-189.2 \pm 0.6$ & $31(21)$ & $-189.3 \pm 0.2$ & $20(13)$ \\
\hline
\end{tabular}

The values in parentheses are the number of measurements not rejected in the statistical treatment

The measurements were normalized using the twopoint linear normalization method proposed by Coplen et al. [22]. A linear regression equation is used to normalize the measurement of the $\delta$ values of GISP, PB3 and PB4 regarding the isotopic reference VSMOW-SLAP scale. Following the principle of identical treatment, the standards and samples undergo the same analytical process. Such a standardization, $\delta^{\top}=a \delta^{\mathrm{M}}+b$, where $\delta^{\top}$ is the true value and $\delta^{\mathrm{M}}$ is the measured value, assumes that any systematic error introduced during analysis is linear for the CRDS method and IRMS.

From the analysis of the distribution of data, the measurements that did not show a normal distribution were not referenced by their weighted average, but by their median value due to the asymmetry of the distribution. The asymmetry was observed in GISP for measurements of $\delta^{18} \mathrm{O}$ with IRMS and CRDS, in PB3 for measurements of $\delta^{2} \mathrm{H}$ and $\delta^{18} \mathrm{O}$ with IRMS and in PB4 for measurements of $\delta^{2} \mathrm{H}$ and $\delta^{18} \mathrm{O}$ with IRMS and CRDS. These results (without the statistical treatment), for each separate system, are presented in Table 1. Table 2 shows the final results obtained after 
Table 3 Isotopic values for the default GISP and work patterns PB3 and PB4 for the CRDS and IRMS methods with all results combined for calibration of secondary standards in the application of the statistical treatment

\begin{tabular}{llccr}
\hline Samples & $\delta^{18} \mathrm{O}_{\text {VSMOW-SLAP }} \pm \mathrm{S}_{\delta}(\%)$ & $N$ & $\delta^{2} \mathrm{H}_{\text {VSMOW-SLAP }} \pm \mathrm{S}_{\delta}(\%)$ & $n$ \\
\hline PB3 & $-2.19 \pm 0.24$ & $195(95)$ & $-1.9 \pm 0.4$ & $104(30)$ \\
PB4 & $-10.08 \pm 0.19$ & $193(81)$ & $-71.4 \pm 0.4$ & $111(35)$ \\
GISP & $-24.69 \pm 0.20$ & $89(39)$ & $-189.3 \pm 0.5$ & $53(19)$ \\
\hline
\end{tabular}

The values in parentheses are the number of rejected measurements in stages of the statistical treatment

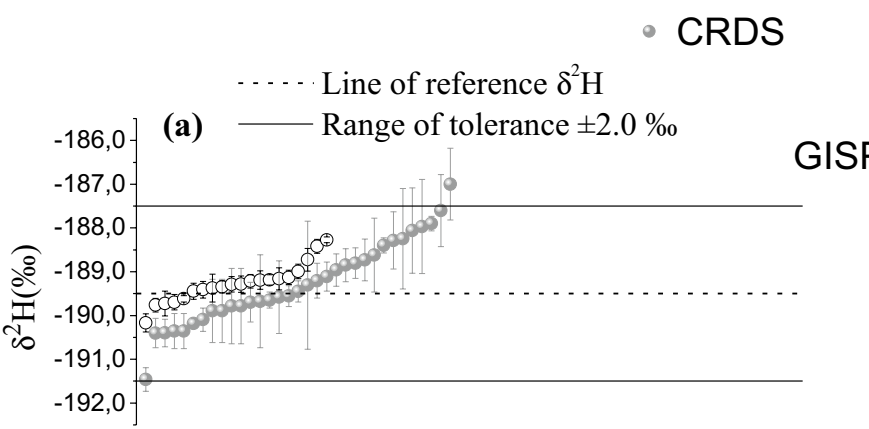

(b)

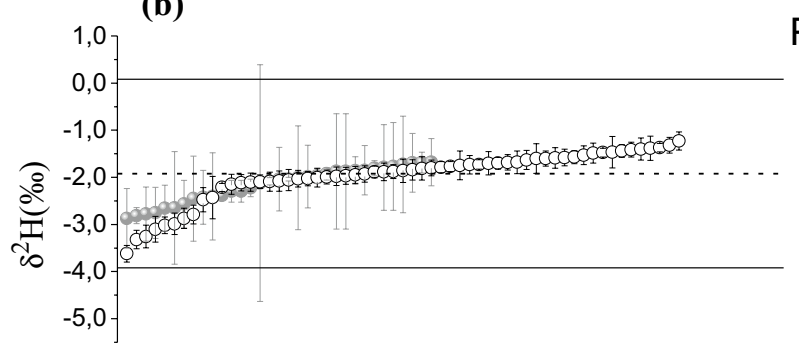

(c)

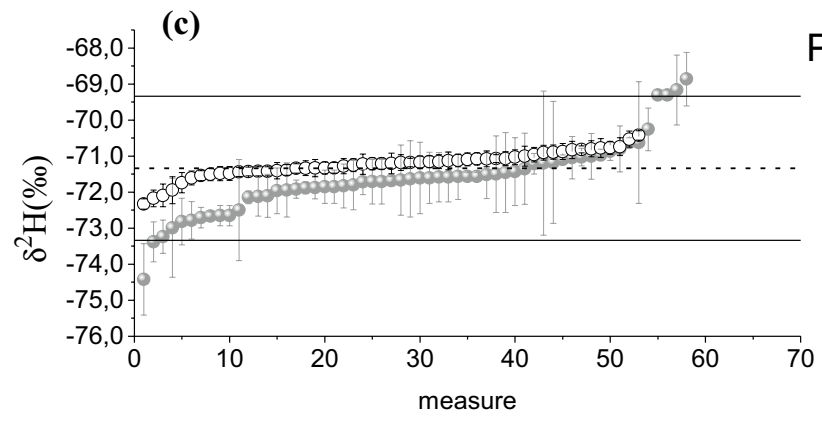

Fig. 6 In this image, open circles are the measurements obtained using IRMS and the grey spheres are the measurements made using CRDS. a, $\mathbf{d}$ The range of values for $\delta^{18} \mathrm{O}$ and $\delta^{2} \mathrm{H}$ in the GISP for both methods within the range of tolerance. $\mathbf{b}$, e The range of

applying the statistical method of the inter-comparison exercise of the IAEA, with the analysis of the distribution of data. Asymmetric distributions were found in PB4 for $\delta^{2} \mathrm{H}$ and $\delta^{18} \mathrm{O}$ using CRDS and IRMS. Table 3 shows the results for the international standard, GISP, and the working standards, PB3 and PB4. In this table, all the results were combined, and the statistical treatment and normality test
- IRMS

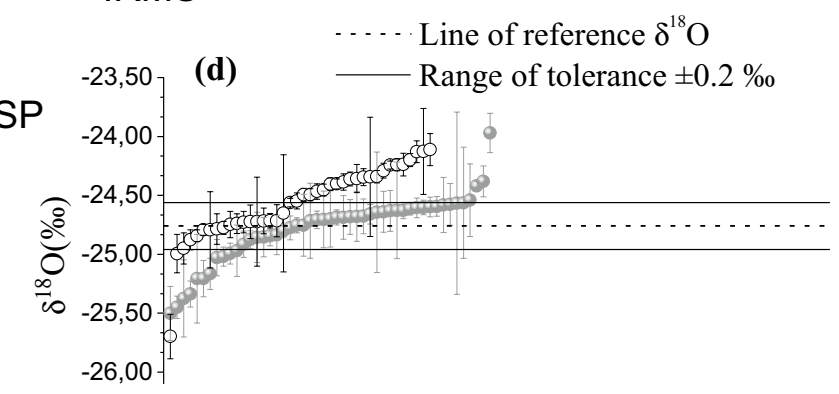

PB3

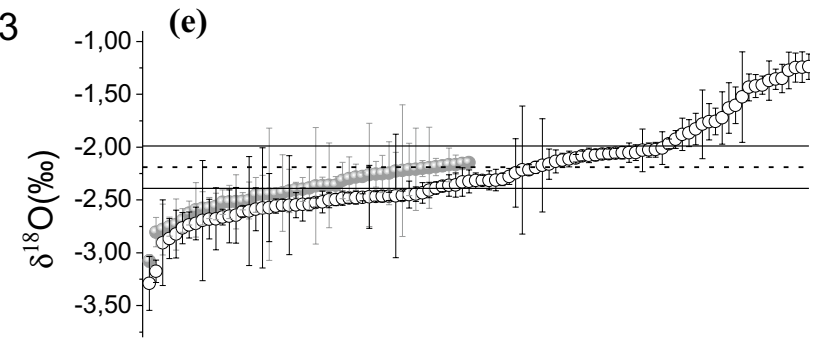

(f)

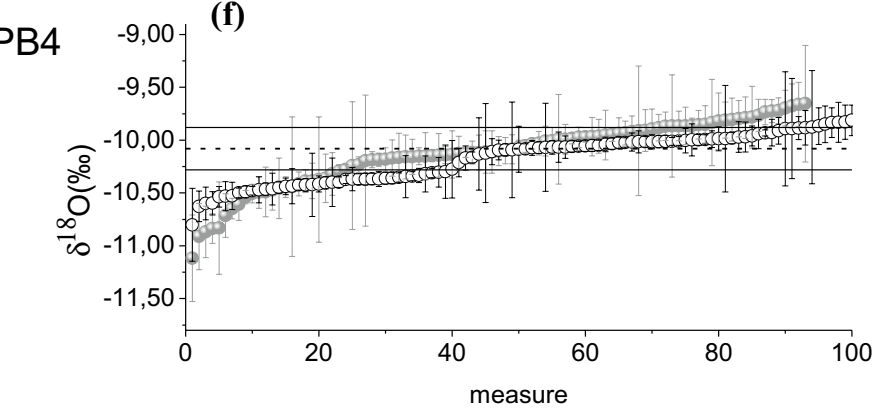

values for $\delta^{18} \mathrm{O}$ and $\delta^{2} \mathrm{H}$ in $\mathrm{PB} 3$ for both methods within the range of tolerance. $\mathbf{c}, \mathbf{f}$ The range of values for $\delta^{18} \mathrm{O}$ and $\delta^{2} \mathrm{H}$ in PB4 for both methods within the range of tolerance

were applied. It was verified that the population does not follow a normal distribution for both $\delta^{18} \mathrm{O}$ and $\delta^{2} \mathrm{H}$.

Figure 6 shows the distributed values for the two methods, CRDS and IRMS. It is found that both methods follow the same behaviour. However, as shown, the error bars for the measurements taken with the laser system are greater for $\delta^{2} \mathrm{H}$. 
Table 4 Statistical tests and results of $p$ value measurements of $\delta^{2} \mathrm{H}$ and $\delta^{18} \mathrm{O}$ performed with CRDS and IRMS for PB3 and PB4 samples and GISP

\begin{tabular}{|c|c|c|c|c|c|c|}
\hline \multirow[t]{2}{*}{ Samples } & \multicolumn{3}{|l|}{$\delta^{2} \mathrm{H}$} & \multicolumn{3}{|l|}{$\delta^{18} \mathrm{O}$} \\
\hline & PB3 & PB4 & GISP & PB3 & PB4 & GISP \\
\hline$T$ test & $x$ & & $x$ & $x$ & & \\
\hline Wilcoxon & & $x$ & & & $x$ & $X$ \\
\hline$p$ value & 0.4217 & $3.28 \times 10^{-7}$ & 0.2492 & 0.003399 & 0.6621 & 0.006845 \\
\hline
\end{tabular}

This is due to the influence of a large memory effect found in this system, primarily for hydrogen. Statistical tests were conducted to check if the averages of the two populations (average obtained in CRDS and IRMS) are equal. For this, we used the $T$ test (parametric) and the Wilcoxon-Mann-Whitney test (nonparametric). The tests were performed using R software [6]. For parametric tests, it is necessary that the data from a population have a normal distribution. The nonparametric test does not depend on the population distribution of the data. However, for both, the sample is random. The hypotheses for the two independent populations (CRDS and IRMS) were: $\mathrm{H}_{0}$-the two samples are from the same population, and $H_{1}$-the two samples come from different populations. The decision rule is to reject the null hypothesis if the $p$ value is less than the significance level $a=0.05$. The $T$ test was applied when the use requirements were served (normal condition). If the conditions for the $T$ test were not satisfied, then Wilcoxon-Mann-Whitney test were applied. Applying the tests on the results after processing the data, it was found that the null hypothesis was rejected for PB4 ( $p$ value $\left.=2.38 \times 10^{-7}\right)$ in measurements of $\delta^{2} \mathrm{H}$ and for PB3 $(p$ value $=0.003399)$ and GISP ( $p$ value $=0.006845)$ in measurements of $\delta^{18} \mathrm{O}$.

Table 4 shows the tests applied to PB3, PB4 and GISP for $\delta^{18} \mathrm{O}$ and $\delta^{2} \mathrm{H}$, as well as their $p$ values. The comparison of the empirical data distribution of the two groups can be visually verified with the box plot.

Points outside these limits are found to be discrepant values or outliers. The box plot was used for a visual comparison of two populations (CRDS and IRMS). In Fig. 7, comparisons are presented between the measured data sets of CRDS and IRMS for $\delta^{2} \mathrm{H}$ and $\delta^{18} \mathrm{O}$. Analysing the box plot reveals that there are disparate points that promote the difference between the medians.

The box plot is used to assess the variance between the empirical data sets. The box plot is formed by the first and third quartiles and the median. The lower and upper stems extend, respectively, from the lower quartile to the smallest value not less than the lower limit and from the upper quartile to the highest value that does not exceed the upper limit. The limits are calculated: lower bound $=Q_{1}-1.5\left(Q_{3}-Q_{1}\right)$ and upper limit $=Q_{3}+1.5\left(Q_{3}-Q_{1}\right)$.
This might be related to the fractionation process and/ or memory effect. GISP was used for quality control or to assess success of the calibration. Figure 8 shows the values for both methods, treated together, and the benchmark for the standard certified GISP $\left(\delta^{2} \mathrm{H}=-189.5 \pm 1.2 \%\right.$ and $\delta^{18} \mathrm{O}=-24.76 \pm 0.09 \%$ ). Some values could not be displayed due to the chosen scale. The values do not differ substantially from the reference value within the range of tolerance in isotope hydrology. However, the value of $\delta^{18} \mathrm{O}$ in IRMS was on the threshold of tolerance. This is due to the possible effects of fractionation in the isotope balance in the preparation process.

\section{Conclusion}

To date, only optical methods can measure the isotopic compositions of the oxygen and hydrogen in water simultaneously and without any pre-treatment. Kerstel et al. [23] reported the first simultaneous determination of $\delta^{2} \mathrm{H}, \delta^{17} \mathrm{O}$ and $\delta^{18} \mathrm{O}$ by means of infrared laser spectroscopy.

It can be concluded that there is a difference between populations, i.e. there is a difference between the methods. This may be associated with potential system interference fluctuations due to contamination, a memory effect, fractionation, the $\mathrm{H}_{3}^{+}$factor and temperature.

However, the averages and medians obtained from both methods are within the range of tolerance in hydrological studies.

Thus, it can be concluded that the secondary standards PB3 and PB4 are well determined and that the CRDS technique presents a promising alternative for determining hydrogen and oxygen isotopes in water samples. However, laser methodology, which is conceptually simpler, does not require much physical space for the installation of equipment, requires less time for analysis, is less expensive and does not require the pre-treatment of samples, excluding a major source of errors due to possible isotopic fractionation. In addition, in situ measurements are possible, something impractical for IRMS. Furthermore, this technology ensures that only the spectrum of the substance of interest is recorded, which reduces interference from other species. 

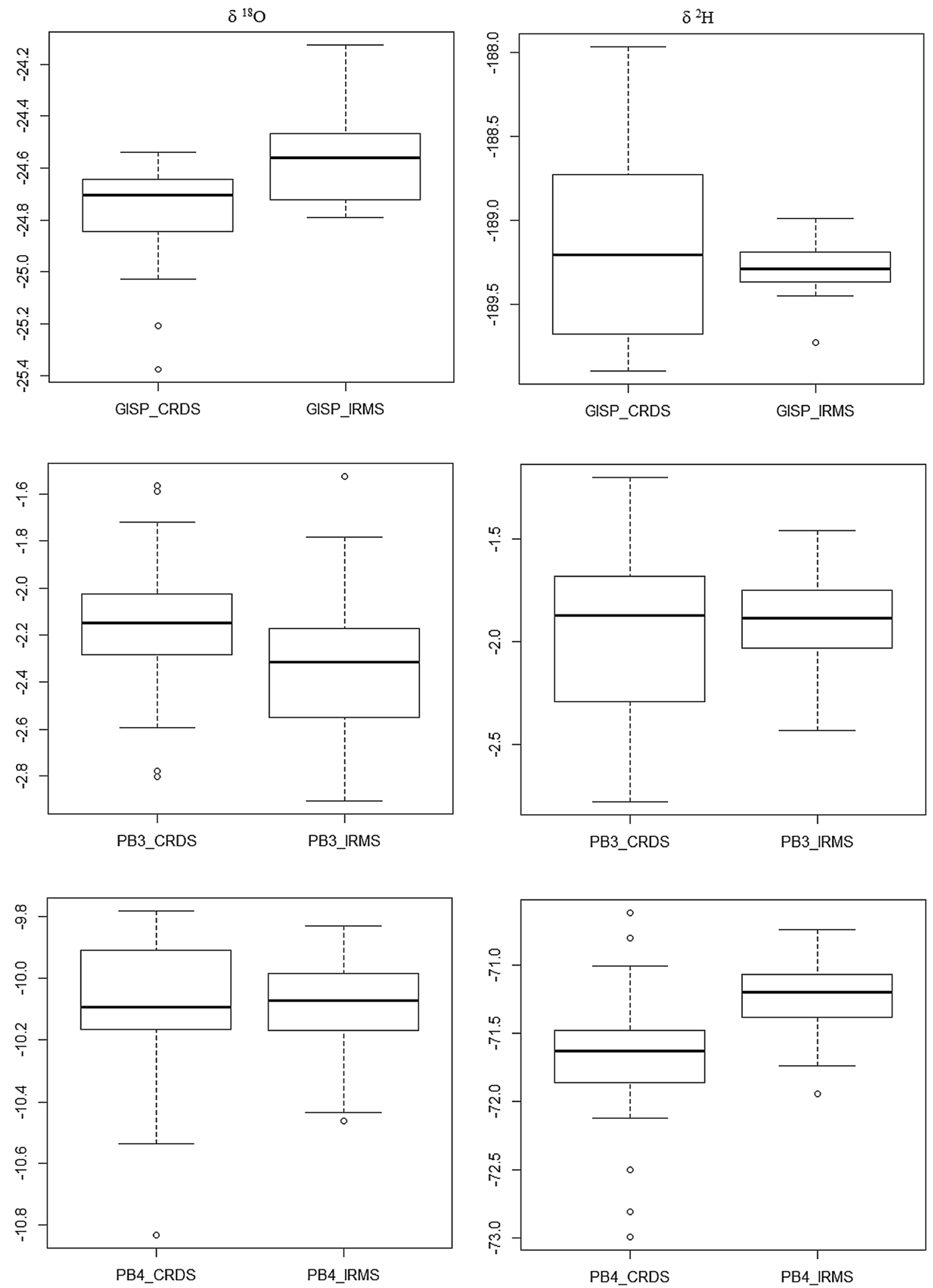

Fig. 7 Box plot in left side shows the variation in the values of $\delta^{18} \mathrm{O}$ in GISP, PB3 and PB4. The box plot in right side shows the variation in the values of $\delta^{2} \mathrm{H}$ in GISP, PB3 and PB4. The open circles are the outlier data, and the gross line is the median value 


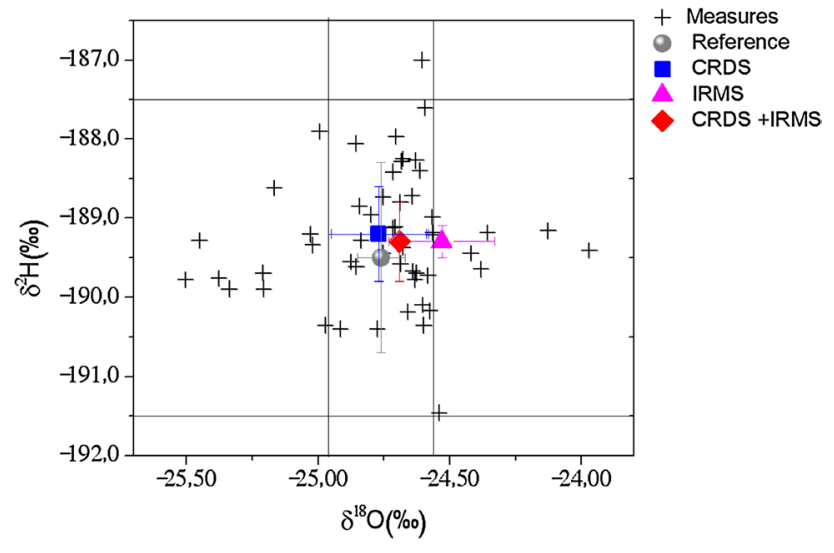

Fig. 8 Comparison of all values for both methods, treated together (CRDS and IRMS), and the reference value for the default GISP certificate. The vertical and horizontal lines represent the ranges of tolerance for $\delta^{18} \mathrm{O}$ and $\delta^{2} \mathrm{H}$, respectively

Acknowledgements This study was funded by Coordination for the Improvement of Higher Level Personnel (Coordenação de Aperfeiçoamento de Pessoal de Nível Superior-CAPES) for granting their support during the postgraduate course at Universidade Federal da Bahia.

\section{Compliance with ethical standards}

Conflict of interest The authors declare that they have no conflict of interest.

\section{References}

1. Dansgaard W (1964) Stables isotopes in precipitation. Tellus 16(4):436-468

2. Johsen SJ, Dahl-Jensen D, Dansgaard W, Gundestrup N (1995) Greenland palaeotemperatures derived from GRIP bore hole temperature and ice core isotope profiles. Tellus 47B:624-629

3. Ciais $\mathrm{P}$, Meijer HAJ (1998) The ${ }^{18} \mathrm{O} /{ }^{16} \mathrm{O}$ isotope ratio of atmospheric $\mathrm{CO}_{2}$ and its role in global carbon cycle research. In: Griffiths $\mathrm{H}$ (ed) Stable isotopes: integration of biological, ecological and geochemical processes. Bios, Oxford, pp 409-431

4. Van Trigt R, Kerstel ERT, Visser GH, Meijer HAJ (2001) Stable isotope ratio measurements on highly enriched water samples by means of laser spectrometer. Anal Chem 73:2445-2452

5. Zalicki P, Zare RN (1995) Cavity ring-down spectroscopy for quantitative absorption measurements. J Chem Phys 102:2708-2717

6. http://www.r-project.org/

7. Ahmad M, Aggarwal $P$, van Duren M, Poltenstein L, Araguas L, Kurttas K, Wassenaar LI (2012) Fourth interlaboratory comparison exercise for $\delta^{2} \mathrm{H}$ and $\delta^{18} \mathrm{O}$ analysis of water samples (WICO2011). IAEA report, Vienna
8. Araguás L, Rozanski K (1995) Interlaboratory comparison for deuterium and oxygen-18 analysis of precipitation samples (report). International Atomic Energy Agency, Vienna, pp 1-33

9. Gröning M, Graeber S, Bhattacharya SK, van Duren M, Andreescu $L$ (2003) Third interlaboratory comparison exercise for $\delta D$ and $\delta^{18} \mathrm{O}$ analysis of water samples (WICO2002-Part 1), vol 43. IAEA report, Vienna

10. Lippmann J, Gröning M, Rozanski K (1999) Second interlaboratory comparison for deuterium and oxygen-18 analysis of water samples, vol 44. IAEA report, Vienna

11. Epstein S, Mayeda T (1953) Variation of O18 content of waters from natural sources. Geochima e Cosmochimica Acts 4:213-224

12. Craig H (1957) Isotopic standards for carbon and oxygen and correction factors for mass spectrometric analysis of carbon dioxide. Geochima e Cosmochimica Acts 12:133-149

13. Brand WA, Avak H, Seedorf R, Hofmann D, Conradi T (2000) New methods for fully automated isotope ratio determination from hydrogen at the natural abundance level. Geophys Prospect 28:967-976

14. Groot PA (2009) Handbook of stable isotope analytical techniques, vol 2. Elsevier, Amsterdam

15. Sessions AL, Burgoyne TW, Hayes JM (2001) Determination of the $\mathrm{H} 3$ factor in hydrogen isotope ratio monitoring mass spectrometry. Anal Chem 73:200-207

16. Kerstel $E$ (2004) Isotope ratio infrared spectrometry (Chapter 34). In: de Groot PA (ed) Handbook of stable isotope analytical techniques. Elsevier, Amsterdam

17. Berden G, Engeln R (2009) Cavity ring-down spectroscopy-techniques and applications. Wiley, London

18. Kerstel ERT, lannone RQ, Chenevier $M$, Kassi S, Jost HJ, Romanini $D$ (2006) A water $(2 \mathrm{H}, 170$, and 180) spectrometer based on optical feedback cavity-enhaced absorption for in situ airbone applications. Appl Phys B 85:397-406

19. Kerstel E, Gianfrani L (2008) Advances in laser-based isotope ratio measurements: selected applications. Appl Phys B 92:439-449

20. Rothman S, Jacquemart D, Barbe A, Benner DC, Birk M, Brown LR, Carleer MR, Chackerian C Jr, Chance K, Coudert LH, Dana V, Devi VM, Flaud JM, Gamache RR, Goldman A, Hartmann JM, Jucks KW, Maki AG, Mandin JY, Massie ST, Orphal J, Perrin A, Rinsland CP, Smith MAH, Tennyson J, Tolchenov RN, Toth RA, Auwera JV, Varanasi P, Wagner GJ (2005) The HITRAN 2004 molecular spectroscopic database. Quantum Spectrosc Radiat Transf 96:139-204

21. Brand WA (2004) Mass spectrometer Herdware for analyzing stable isotope ratios. In: Groot PA (ed) Handbook of stable isotope analytical techniques, Chap 38, vol 1. Elsevier, Amsterdam

22. Coplen TB (1988) Normalization of oxygen and hydrogen isotope data. Chem Geol (Isotop Geosci Sect) 72:293

23. Kerstel ERT, Van Trigt R, Dam N, Reuss J, Meijer HAJ (1999) Laser spectrometry applied to the simultaneous determination of the ${ }^{2} \mathrm{H},{ }^{17} \mathrm{O}$, and ${ }^{18} \mathrm{O}$ isotope abundances in water. Centrum Voor Isotopenonderzoek, University of Groningen, Groningen, Netherlands. New Approaches for Stable Isotope Ratio Measurements, 1999, IAEA

Publisher's Note Springer Nature remains neutral with regard to jurisdictional claims in published maps and institutional affiliations. 